\title{
Clinical Outcome Assessment Criterion Validation
}

National Cancer Institute

\section{Source}

National Cancer Institute. Clinical Outcome Assessment Criterion Validation. NCI

Thesaurus. Code C156634.

A performance outcome measure that assesses the degree to which the scores of a

clinical outcome assessment instrument are related to a known gold standard measure

of the same concept. 